\title{
Octagonal Microstrip Patch antenna array with gain enhancement for WiMAX and WLAN Applications
}

\author{
Abdullahi Auwal Gabari 1 (iD), Zainab Yunusa 2*iD, Mohd Nizar Hamidon ${ }^{3}$ iD \\ ${ }^{1}$ Federal Polytechnic of Oil and Gas Bonny, Department of Electrical and Electronics Engineering, Rivers, Nigeria \\ 2 Bayero University Kano, Department of Electrical Engineering, Kano, Nigeria \\ 3 Universiti Putra Malaysia, Institute of Advanced Technology, Selangor, Malaysia
}

Cite this paper as:

Gabari, A.A., Yunusa, Z., Hamidon, M. N. (2019). Octagonal Microstrip Patch antenna array with gain enhancement for WiMax and WLAN Applications. Journal of Innovative Science and Engineering. 3(2): 27-39.

*Corresponding author: Zainab Yunusa E-mail: zee2yunusa@gmail.com

Received Date: 26/10/2019

Accepted Date: 22/12/2019

(C) Copyright 2019 by

Bursa Technical University. Available online at http://jise.btu.edu.tr/

\section{c) (i) (8)}

The works published in Journal of Innovative Science and Engineering (JISE) are licensed under a Creative Commons Attribution-NonCommercial 4.0 International License.

\begin{abstract}
An octagonal microstrip patch antenna is presented in this paper. A small sized microstrip patch antenna with a high gain has been the focusing point of so many researches over the years. Microstrip patch antenna is basically known to have a low gain as a result various techniques are carried out in order to enhance the gain. In this work, a single patch octagonal microstrip patch antenna and a 1 2 octagonal patch antenna array are designed and the effects are studied. The structure is designed on four different substrates FR4, Duroid, Arlon and Rogers substrate materials. Copper is used as the patch and ground material. The antenna is designed on a small substrate material and it is probe fed. The simulated results of the array reveals a gain increase of $6.25 \mathrm{~dB}$ from $3.6 \mathrm{~dB}$ of the single patch on the FR4 substrate. The simulated results of the antenna in terms of reflection coefficients, voltage standing wave ratio (VSWR) and gains realized showed that the antenna has prospective applications for 4.6 and $5.9 \mathrm{GHz}$ applications. Conclusively, the antenna with the FR4 substrate shows the best antenna performance in terms of Gain and Return loss and its operating frequency falls under the WiMAX and WLAN range compared to the other substrates. The tool used for the design and simulation is the Computer Simulation Technology (CST) microwave studio.
\end{abstract}

Keywords: Octagonal patch; Antenna array; Gain enhancement; WiMAX and WLAN Applications; VSWR; Reflection coefficients. 


\section{Introduction}

The fast decrease in the sizes of our mobile devices leads to the rapid growth of smaller antenna structures. Different antenna configurations are today being used to replace the conventional antenna we use in mobile communication. The multiband distinctiveness of the Microstrip patch antennas and its compact configuration have made it a favorable candidate for handheld electronic devices. A microstrip antenna comprises of a rectangular patch on a ground plane divided by dielectric substrate [1]. The patch in the antenna is made of a conducting material $\mathrm{Cu}$ (Copper) or $\mathrm{Au}$ (Gold) and this can be presented in any shapes of such as rectangular, elliptical, triangular, circular or any other known shapes. In elementary form, a Microstrip Patch antenna as presented in fig 1 comprises of a radiating patch on top of a dielectric substrate which has a ground plane on the bottom. The radiating patch and the feed lines are ordinarily photo etched on the dielectric substrate. The microstrip patch antenna has numerous advantages such as light weight, little cost, simplicity of fabrication etc. Regardless of the numerous advantages of the antenna, a major drawback that microstrip patch antennas undergo is low gain.

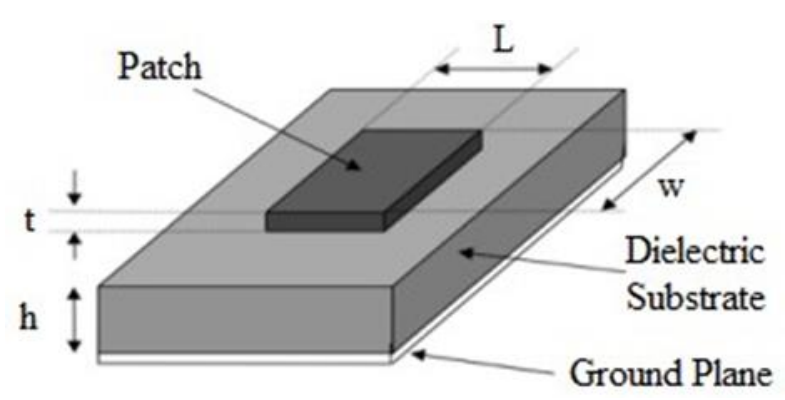

Figure 1. Microstrip Patch Antenna [1]

In the present day, wireless devices have numerous applications which require high gain and these wireless devices are getting thinner and smarter. As a result, the Microstrip antenna used for executing this operation should offer higher gain as well as their shape should be more effectual and size should be compact so that it should occupy less space while keeping the size of device as small as possible. Having a high gain, Microstrip patch antennas have been a challenge as these antennas are known for having a low gain [2]. So many Scholars have studied the Microstrip patch antennas bearing in mind different antenna parameters such as Bandwidth, Gain, Reflection coefficients, Voltage Standing Wave Ratio (VSWR) etc. In their findings, the ways to improve these parameters such as change in dielectric substrate, change in shape of the patch, by means of superstrate, removal of substrate and mixture of different methods were considered. In order to enhance the gain of the Microstrip antenna, array arrangement of the antenna is commonly recommended; A unit comprising of two or more element antennas is known as an Antenna array. Antenna arrays are associated with many good properties, which a single element antenna does not have, such as high gain [3]. An array antenna centers its transmission and reception of energy in one direction, so we have a better radiation energy management and radiation effectiveness in antenna arrays than a single patch [4]. Numerous gain enhancement ways and means have been employed ranging from array configuration where in [5] Musa et al observed a gain increase of $10.1 \mathrm{~dB}$ for $2 \times 4$ array from a gain of $3.08 \mathrm{~dB}$ of a single patch, by introduction of stubs of dissimilar substrate material with a slot [6], by low loss substrate [7], by using defected ground structure (DGS) [8], by having slot in the ground plane where in 2011 
Mouloud et al presented a paper in which they were able to accomplish a gain of $5.9 \mathrm{~dB}$ by etching a slot in the ground plane [9], by redirecting surface waves through the integration of reflectors into the antennas[10] which achieved a gain of $13.2 \mathrm{~dB}$, by incorporating electromagnetic band gap EBG [11] and using meta surfaces where Diego et al presented how graphene improves antenna parameters [12]. M.T.Ali et al designed 2 × 2 microstrip patch antenna with air substrate at $5.8 \mathrm{GHz}$ operating frequency and achieved gain enhancement of gain up to $38.21 \%$ [13]. A gain of $11.5 \mathrm{dBi}$ and $18 \%$ Bandwidth was achieved in [14] by introducing a u slot rectangular 2x2 microstrip patch antenna. A 3 × 2 and $3 \times 3$ array antennas for WiMAX application were designed [15] in which covered $3.3 \mathrm{GHz}$ to $3.8 \mathrm{GHz}$ WiMAX band operating frequency. An Electromagnetic Band Gap (EBG) was integrated on a microstrip patch antenna as a superstrate and a gain of $5.02 \mathrm{~dB}$ was achieved in [16]. Most of these antennas are not suitable to be used in our compact devices because they are large in size. In this paper, the authors present an improved gain compact Octagonal Microstrip patch antenna array for WIMAX and WLAN applications. Single patch $(1 \mathrm{x} 1)$ and two patches array $(1 \mathrm{x} 2)$ were considered in the study. WiMAX belongs to IEEE 802.16 family of standards. The full meaning of WiMAX is; Worldwide Interoperability for Microwave Access. It offers data rate of 30-40 Mbps, permitting us with interoperable operations. There are three licensed spectrum profiles in WiMAX (low band, middle band and high band). The Lower band takes frequency ranging from 2.5 to $2.8 \mathrm{GHz}$, the middle band takes frequency ranging from 3.2 to $3.8 \mathrm{GHz}$ and the higher band takes 5.2 to $5.8 \mathrm{GHz}$. WLAN stands for Wireless Local Area Network and belongs to IEEE 802.11 family of standards covering 2.4/5.2/5.8 GHz bands. WLAN and WiMAX have been usually functional in mobile devices such as smart phones and portable computers. Due to the fast growing of these devices, there is need to provide small antennas that will fit in the devices. These antennas have characteristics like little cost and low profile which proves Microstrip antennas to be seemly for WLAN/WiMAX application systems.

In this paper, the authors proposed an Octagonal Microstrip patch antenna array for WiMAX and WLAN applications. The antenna is designed in three steps. In the first step, a normal rectangular patch antenna is designed. In the second step, we make a small triangular cuts on the four edges of the rectangular patch to have an octagonal shaped antenna, the octagonal shaped antenna when properly arrayed give us a multi band resonances that will cover both the WiMAX and WLAN frequencies. In the third step, a 1x2 array of the antenna is formed which leads us to having a multi band antenna with an appreciable bandwidth and gain.

\section{Antenna Design}

\section{Step 1}

A normal rectangular patch antenna is designed. This antenna is designed on glass epoxy FR4 dielectric material having a relative permittivity ( $\varepsilon r$ ) of 4.3 and with thickness (h) of $1.6 \mathrm{~mm}$. The width of the patch antenna is calculated by using formula [17]

$$
W=\frac{c}{2 f_{c}} \sqrt{\frac{2}{1+\varepsilon_{r}}}
$$


Where

c- Velocity of light in air $=3 \times 10^{8} \mathrm{~m} / \mathrm{s}$.

$\mathrm{f}_{\mathrm{c}}-$ Frequency of antenna $=5 \times 10^{9} \mathrm{~Hz}$.

$\varepsilon_{r}$ - Dielectric constant of substrate

Effective dielectric constant as specified by Hammersted and Jensen [17],

$\varepsilon_{e f f}=\frac{1+\varepsilon_{r}}{2}+\frac{\varepsilon_{r}-1}{2}\left[1+\frac{12 h}{W}\right]^{-1 / 2}$

Owing to the effect of fringing fields, the length (L) increases by $\Delta L$ from physical length, which is given by length extension $(\Delta L)$

$\Delta L=0.412 h \frac{\left(\varepsilon_{e f f}+0.3\right)\left(\frac{W}{h}+0.264\right)}{\left(\varepsilon_{e f f}-0.258\right)\left(\frac{W}{h}+0.8\right)}$

\section{The Effective electrical length of the antenna}

$L_{e f f}=\frac{C}{2 f_{c \sqrt{\varepsilon_{e f f}}}}$

The length of the patch:

$L=L_{e f f}-2 \Delta L$

The Ground plane is given by:

$6 \mathrm{~h}+$ Width of the patch

$6 \mathrm{~h}+$ Length of the patch

The dimensions of conventional patch antenna gotten using the above equations are listed in Table 1 
Table 1. Parameters of single Patch Antenna

\begin{tabular}{|l|l|}
\hline Input parameter & Size (mm) \\
\hline Width of patch & 15.4 \\
\hline Length of patch & 11.92 \\
\hline Thickness of patch & 0.02 \\
\hline Width and length of substrate & $24 \times 21$ \\
\hline Width and Length of ground & $24 \times 21$ \\
\hline Thickness of substrate & 1.6 \\
\hline Thickness of ground plane & 0.02 \\
\hline
\end{tabular}

Step 2- we cut a small triangular shape in the four angles of the rectangular microstrip patch antenna to have an octagonal patch antenna as shown in the figure below (Figure 2).

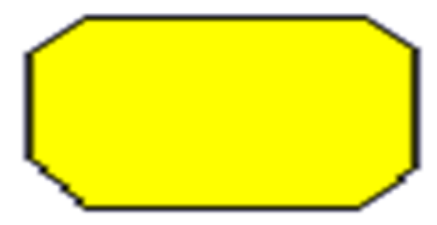

Figure 2. Geometry of single patch antenna

Step3 - an array of the octagonal patch is formed. The array of the antenna is probe fed. The figure below (Figure 3) shows the geometry of $1 \times 2$ array configuration of the antenna.

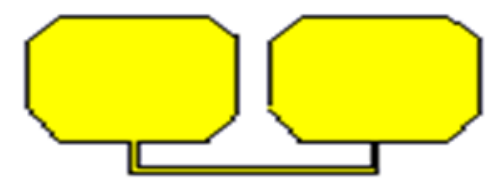

Figure 3. Geometry of $1 \times 2$ array antenna

Table 2. Parameters of $1 \times 2$ array Patch Antenna

\begin{tabular}{|l|l|}
\hline Input parameter & Size (mm) \\
\hline Width and length of substrate & $43 \times 24$ \\
\hline Width and Length of ground & $43 \times 24$ \\
\hline Thickness of substrate & 1.6 \\
\hline
\end{tabular}




\section{Simulated Results}

In this section, there are two simulation results for single patch and for $1 \times 2$ array on four different substrates. The Substrates used for this purpose are FR4, RT Duroid, Arlon, Rogers with dielectric constant of 4.3, 2.2 , 3.5, 10.1 respectively.

a. single patch

i. Bandwidth: Figure $4 \mathrm{a}, \mathrm{b}, \mathrm{c}$ and d shows the bandwidth for the four substrates. In which FR4 resonates at two different frequencies and has a bandwidth of $200 \mathrm{MHz}$ and $500 \mathrm{MHz}$, Duroid resonates once and has a bandwidth of $1200 \mathrm{MHz}$, Arlon resonates once with a bandwidth of $500 \mathrm{MHz}$ and Rogers resonates once and has a bandwidth of $100 \mathrm{MHz}$

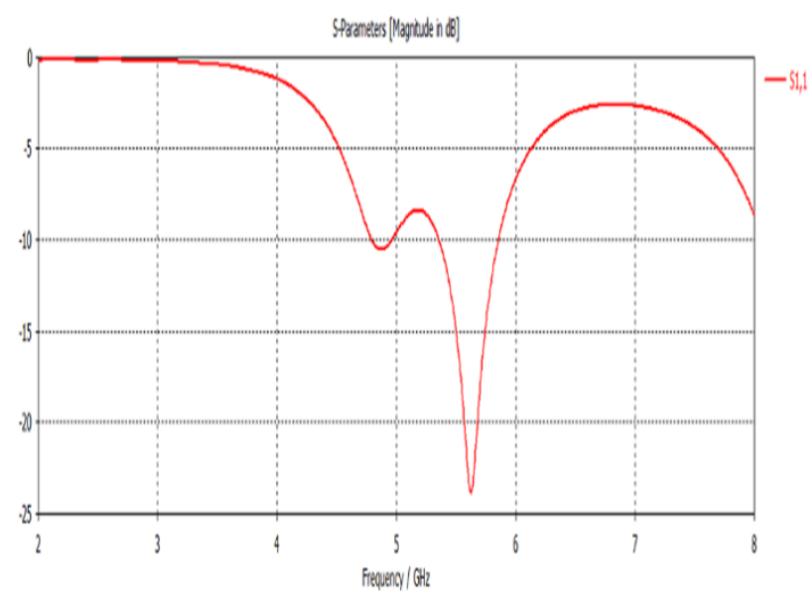

(a)

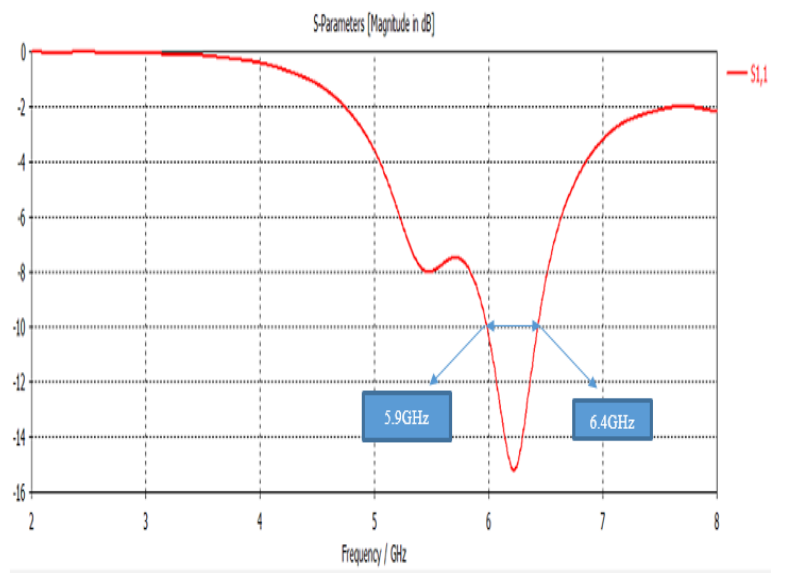

(c)

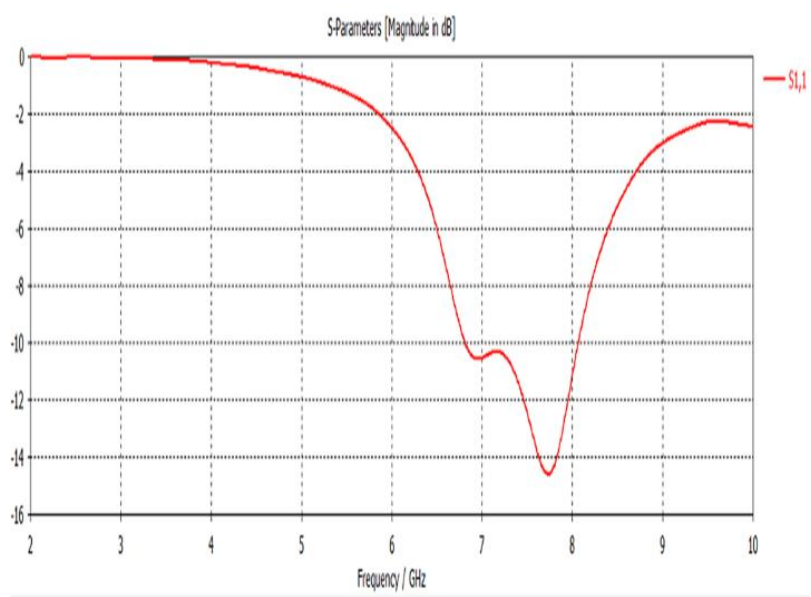

(b)

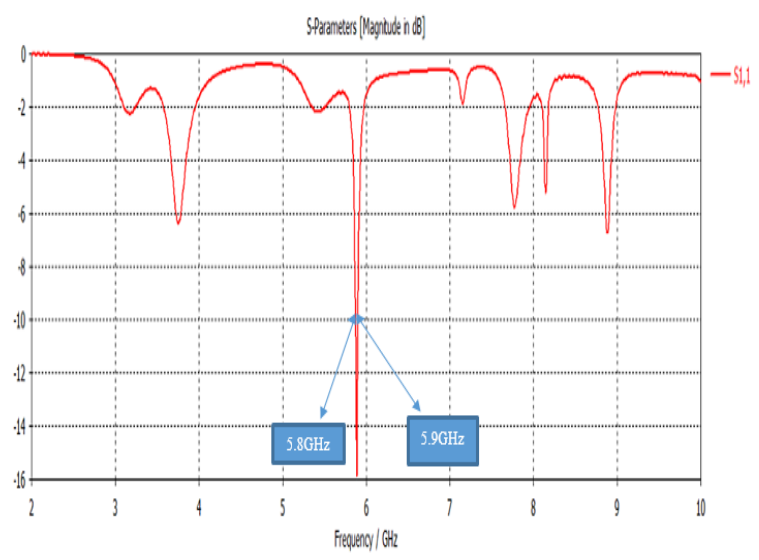

(d)

Figure 4. (a): Bandwidth for FR4 Substrate $\varepsilon=4.3$ (b): Bandwidth for RT Duroid Substrate $\varepsilon=2.2$ (c): bandwidth for Arlon Substrate $\varepsilon=3.5$ (d) Bandwidth for Rogers Substrate $\varepsilon=10.1$ 
ii Voltage Standing Wave Ratio (VSWR): Figure $5 \mathrm{a}, \mathrm{b}, \mathrm{c}$ and d shows the VSWR for the four substrates. In which FR4 has a VSWR of 1.8 and 1.1, Duroid has a VSWR of 1.45, Arlon has a VSWR of 1.4 and Rogers has a VSWR of 1.37 .

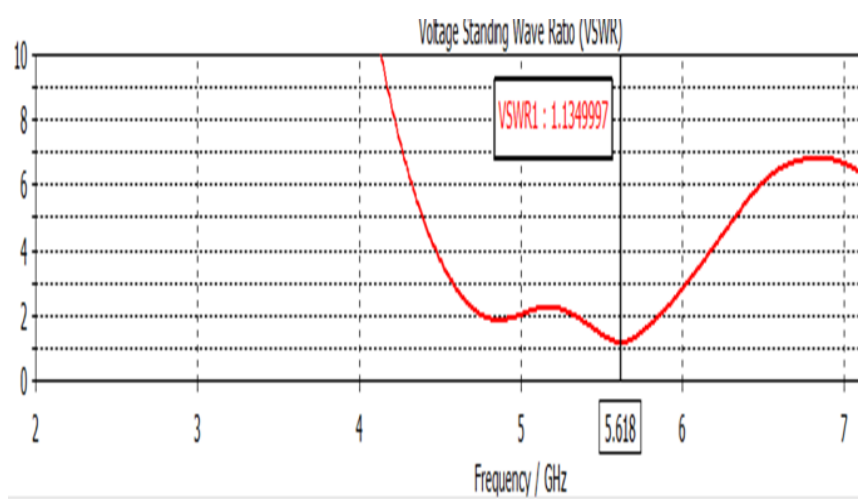

(a)

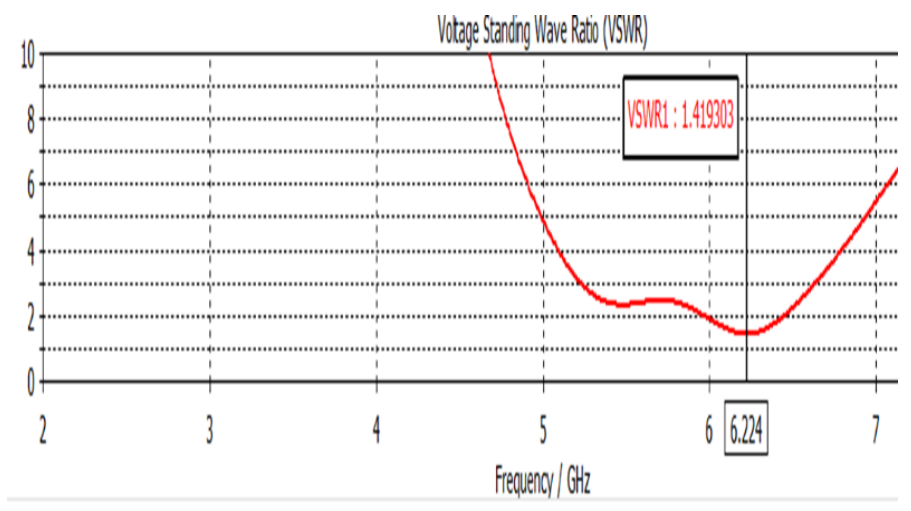

(c)

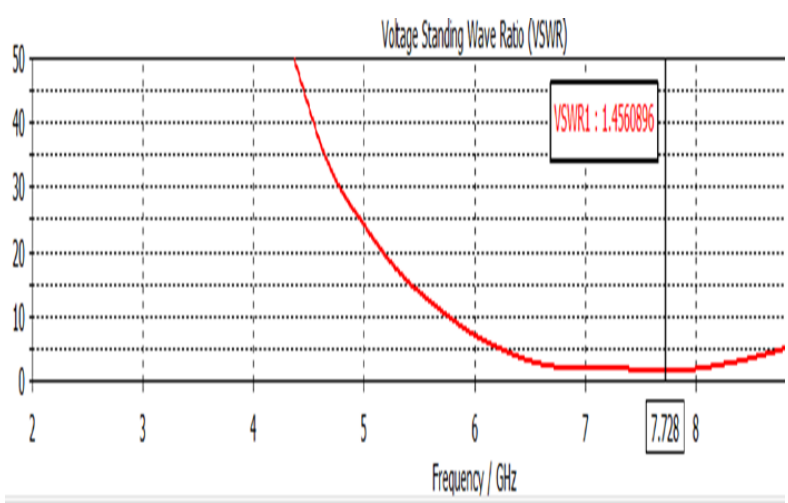

(b)

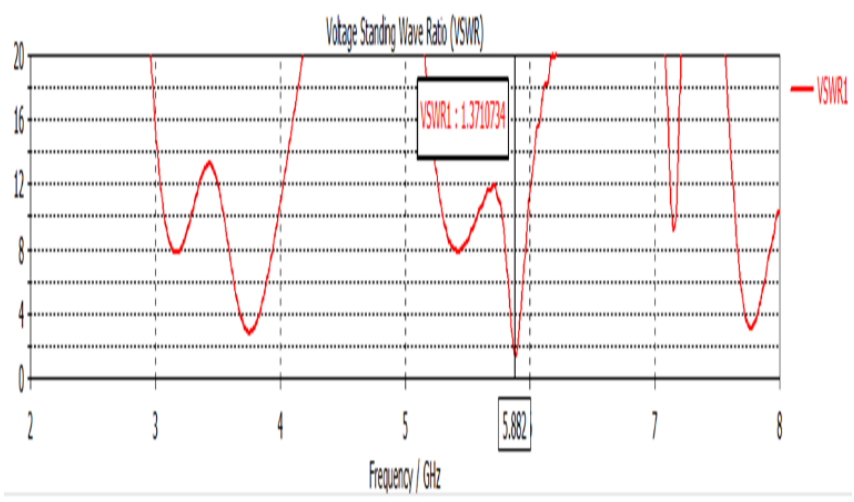

(d)

Figure 5. (a):VSWR for FR4 Substrate $\varepsilon=4.3$ (b): VSWR for RT Duroid Substrate $\varepsilon=2.2$ (c): VSWR for Arlon Substrate $\varepsilon=3.5$ (d)VSWR for Rogers Substrate $\varepsilon=10.1$

iii. Gain: Figures 6 a, b, c and d shows the Gain for the four substrates. In which FR4 has a Gain of 3.6dB, Duroid has a Gain of 7.34dB, Arlon has a Gain of 3.22dB and Rogers has 


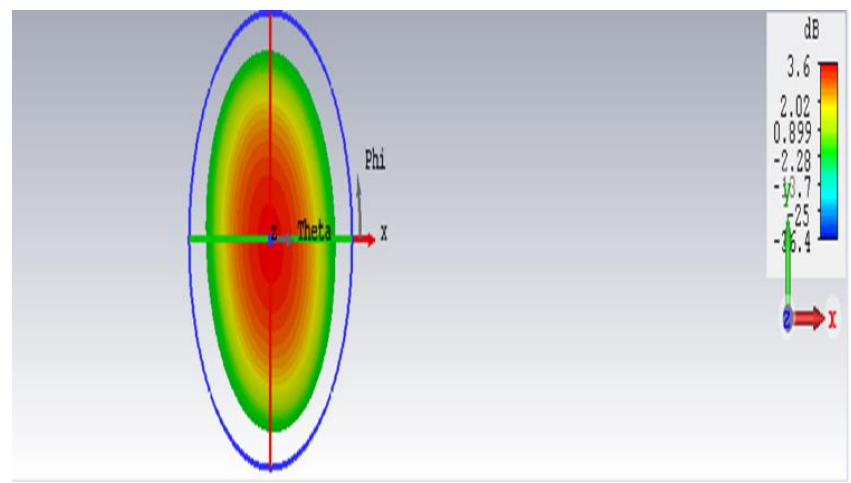

(a)

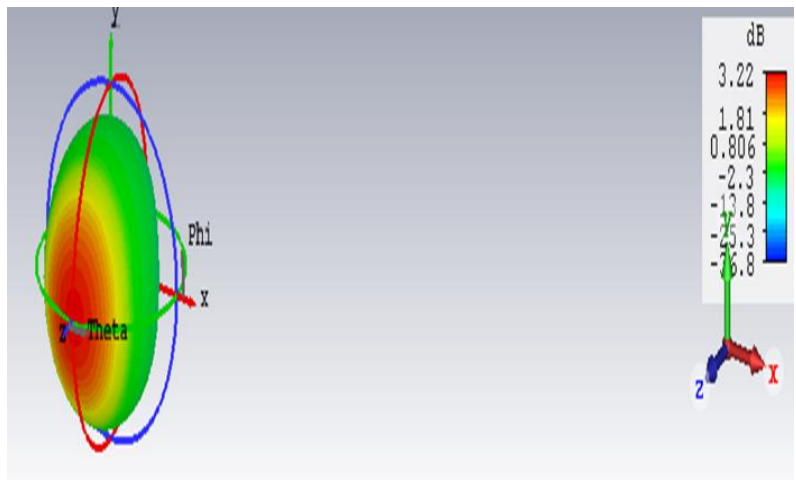

(c)

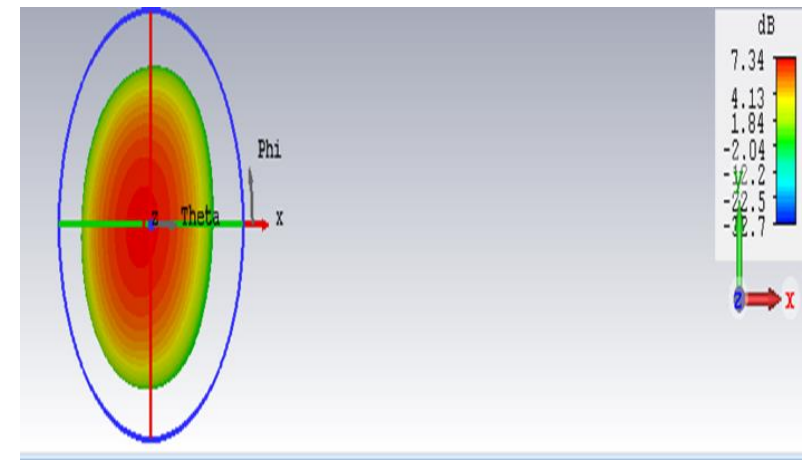

(b)

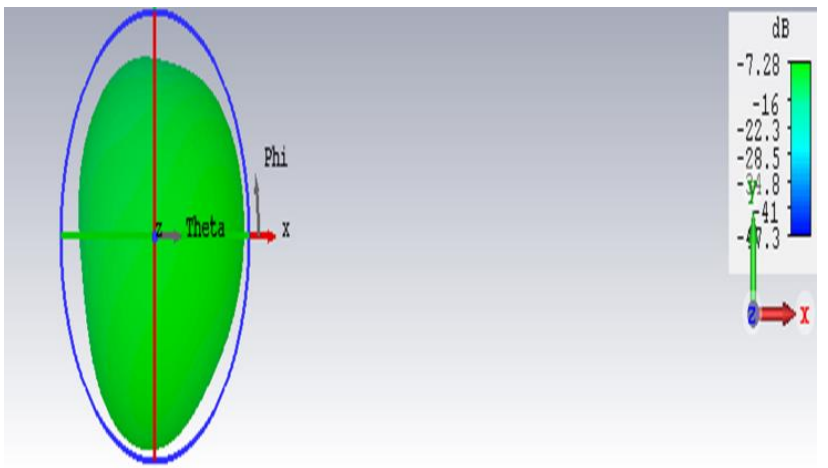

(d)

Figure 6. (a): GAIN for FR4 Substrate $\varepsilon=4.3$ (b): GAIN for RT Duroid Substrate $\varepsilon=2.2$ (c): GAIN for Arlon Substrate $\varepsilon=3.5$ (d) GAIN for Rogers Substrate $\varepsilon=10.1$

B. $1 \times 2$ array

i. $\quad$ Bandwidth: Figure $7 \mathrm{a}, \mathrm{b}, \mathrm{c}$ and d shows the bandwidth for the four substrates. In which FR4 resonates at two different frequencies and has bandwidths of $100 \mathrm{MHz}$ and $600 \mathrm{MHz}$, Duroid resonates twice with bandwidths of $200 \mathrm{MHz}$ and $900 \mathrm{MHz}$, Arlon resonates at four different frequencies with bandwidths of $100 \mathrm{MHz}, 600 \mathrm{MHz}, 300 \mathrm{MHz}$ and $300 \mathrm{MHz}$ and Rogers resonates at five different frequencies with bandwidths of $40 \mathrm{MHz}, 100 \mathrm{MHz}, 100 \mathrm{MHz}, 20 \mathrm{MHz}$ and $20 \mathrm{MHz}$. 


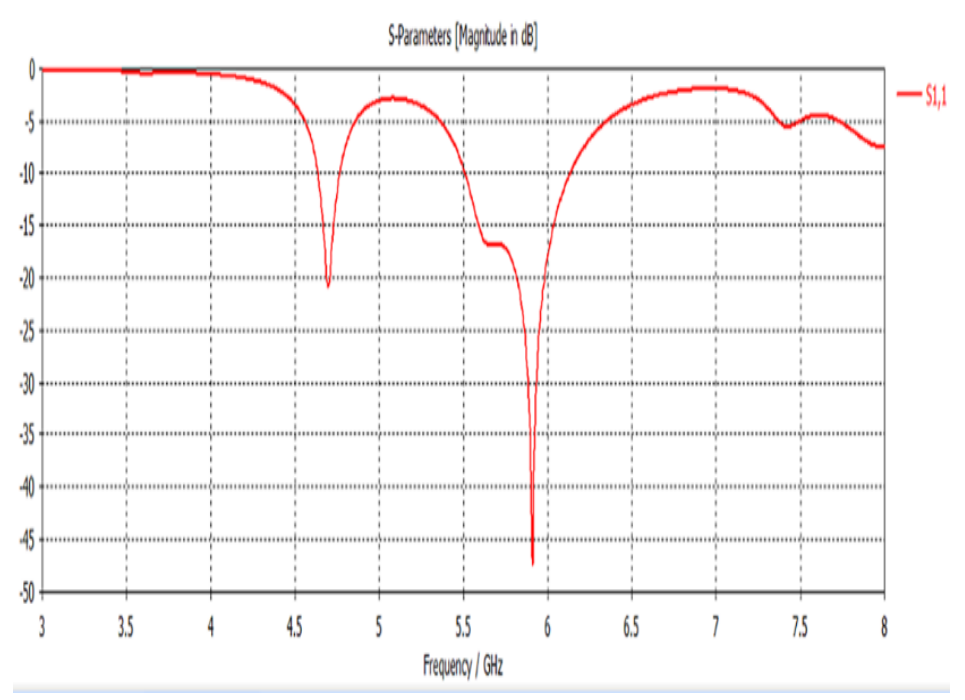

(a)

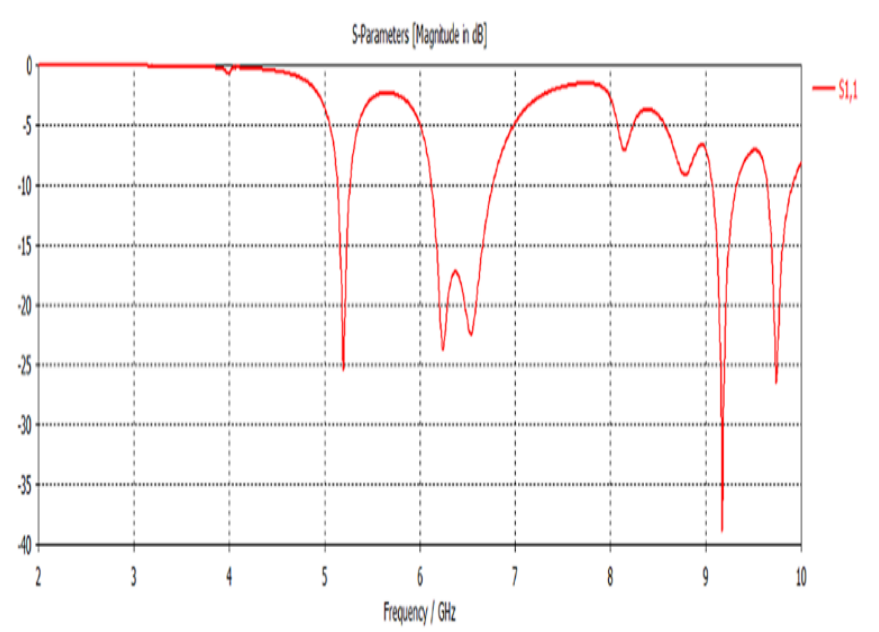

(c)

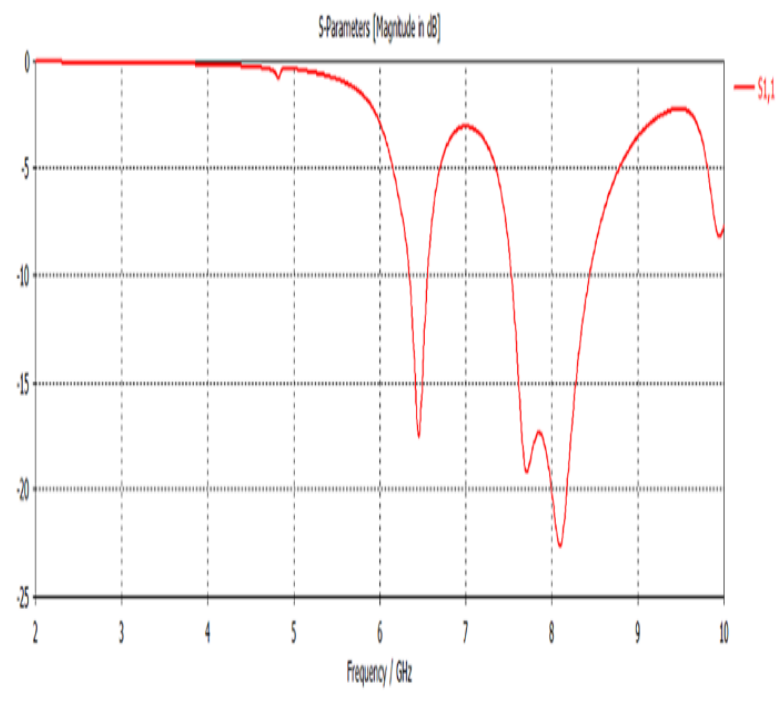

(b)

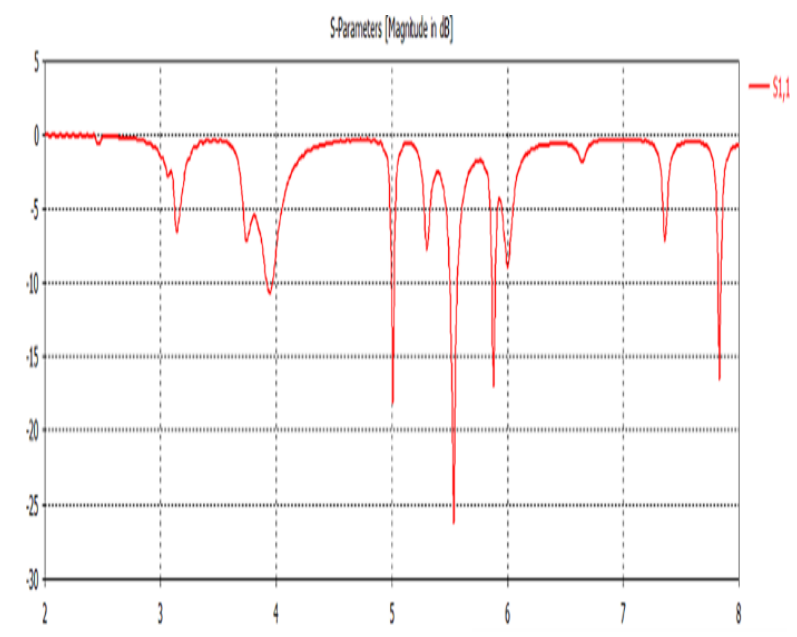

(d)

Figure 7. (a): Bandwidth for FR4 Substrate $\varepsilon=4.3$ (b): Bandwidth for RT Duroid Substrate $\varepsilon=2.2$ (c): bandwidth for Arlon Substrate $\varepsilon=3.5$ (d) Bandwidth for Rogers Substrate $\varepsilon=10.1$

ii. VSWR: Figure 8 a, b, c and d shows the VSWR for the four substrates. In which FR4 has a VSWR of 1.2 and 1.003, Duroid has a VSWR of 1.31 and 1.15, Arlon has a VSWR of 1.14, 1.1, 1.02 and 1.2 and Rogers has a VSWR of 1.8, 1.2, 1.06, 1.3 and 1.3. 


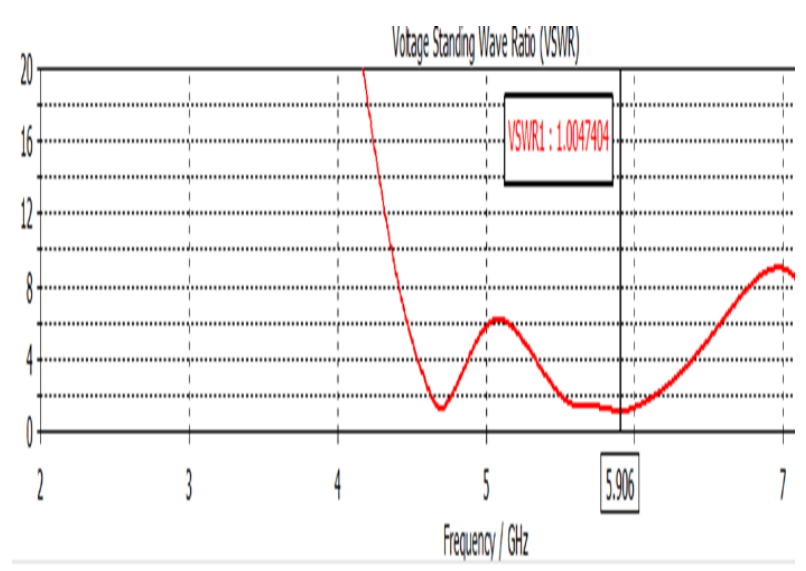

(a)

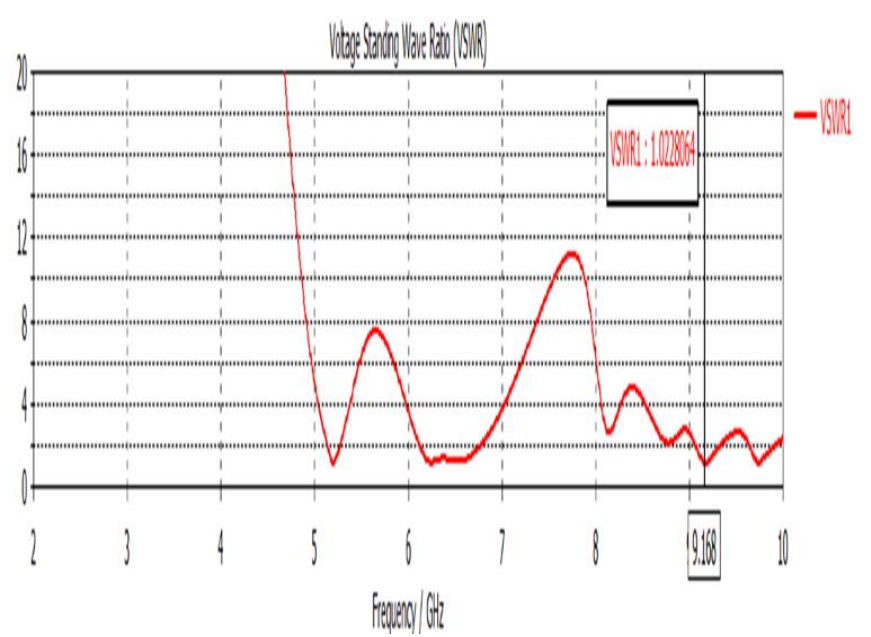

(c)

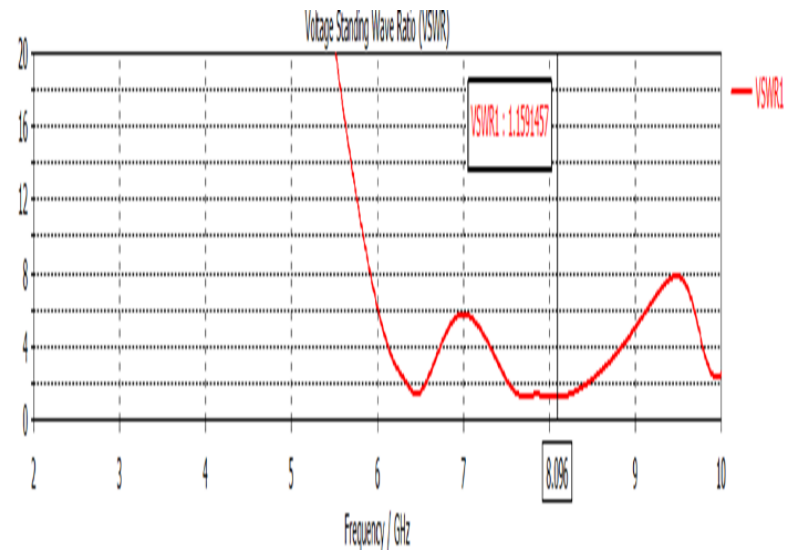

(b)

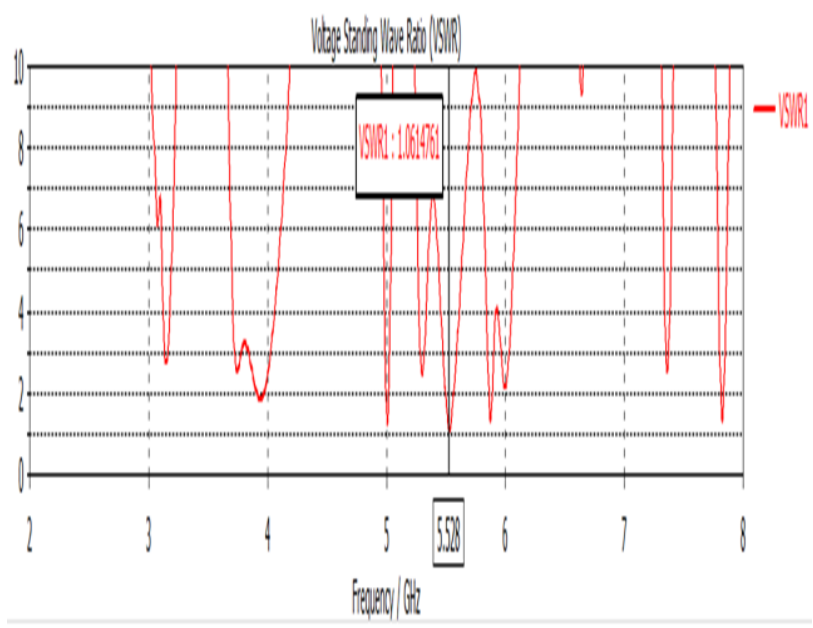

(d)

Figure 8. (a): VSWR for FR4 Substrate $\varepsilon=4.3$ (b): VSWR for RT Duroid Substrate $\varepsilon=2.2$ (c): VSWR for Arlon Substrate $\varepsilon=3.5$ (d) VSWR for Rogers Substrate $\varepsilon=10.1$

iii. Gain: Figure 9 a, b, c and d shows the Gain for the four substrates. In which FR4 has a Gain of 6.25dB, Duroid has a Gain of $4.17 \mathrm{~dB}$, Arlon has a Gain of $4.37 \mathrm{~dB}$ and Rogers has a Gain of $2.48 \mathrm{~dB}$ 


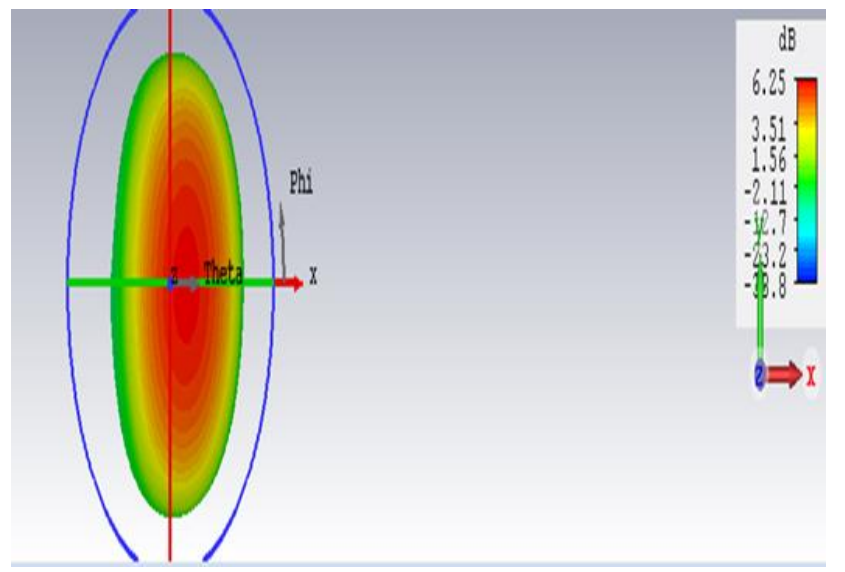

(a)

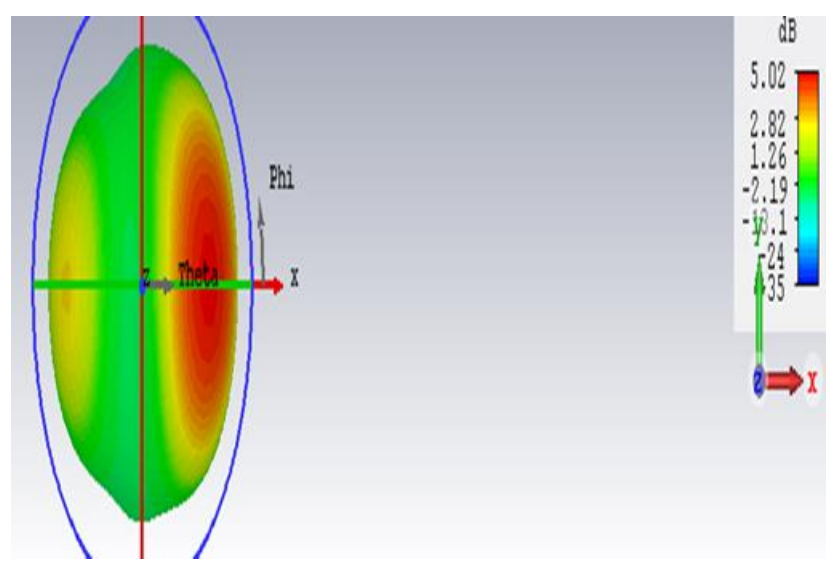

(c)

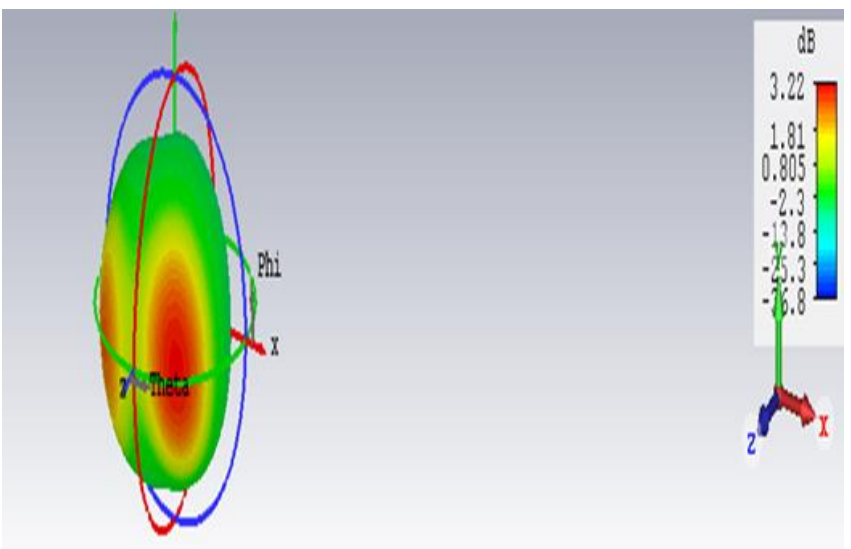

(b)

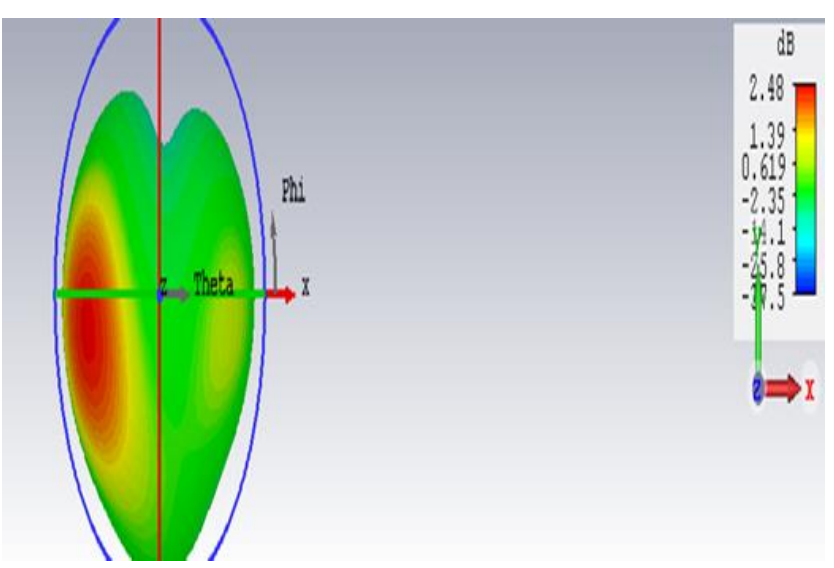

(d)

Figure 9. (a): GAIN for FR4 Substrate $\varepsilon=4.3$ (b): GAIN for RT Duroid Substrate $\varepsilon=2.2$ (c):GAIN for Arlon Substrate $\varepsilon=3.5$ (d) GAIN for Rogers Substrate $\varepsilon=10.1$

Table 3. Table of results for single patch

\begin{tabular}{|c|c|c|c|c|}
\hline Parameters & FR4 & RT Duroid & Arlon & Rogers \\
\hline Operating Frequency $(\mathrm{GHz})$ & $\begin{array}{l}4.7-4.9 \\
5.3-5.8\end{array}$ & $6.8-8.0$ & $5.9-6.4$ & $5.8-5.9$ \\
\hline Return Loss (in dB) & $\begin{array}{l}-10.5 \\
-23.9\end{array}$ & -14.6 & -15.4 & -16.1 \\
\hline Gain in (in dBi) & 3.6 & 7.34 & 3.22 & -7.28 \\
\hline Bandwidth (MHz) & $\begin{array}{l}200 \\
500\end{array}$ & 1200 & 500 & 10 \\
\hline VSWR & $\begin{array}{l}1.8 \\
1.1\end{array}$ & 1.45 & 1.4 & 1.37 \\
\hline
\end{tabular}


Table 4. Table of results for $1 \times 2$ array

\begin{tabular}{|c|c|c|c|c|}
\hline Parameters & FR4 Glass Epoxy & RT Duroid & Arlon & Rogers \\
\hline Operating Frequency $(\mathrm{GHz})$ & $\begin{array}{l}4.6-4.7 \\
5.5-6.1\end{array}$ & $\begin{array}{l}6.3-6.5 \\
7.5-8.4\end{array}$ & $\begin{array}{l}5.1-5.2 \\
6.1-6.7 \\
9-9.3 \\
9.6-9.9\end{array}$ & $\begin{array}{l}3.92-3.96 \\
4.9-5 \\
5.4-5.5 \\
5.86-5.88 \\
7.81-7.83\end{array}$ \\
\hline Return Loss (in dB) & $\begin{array}{l}-20.1 \\
-52.5\end{array}$ & $\begin{array}{l}-17.2 \\
-22.6\end{array}$ & $\begin{array}{l}-23 \\
-23.2 \\
-38.9 \\
-24.5\end{array}$ & $\begin{array}{l}-10.6 \\
-19.5 \\
-30.5 \\
-16.9 \\
-17\end{array}$ \\
\hline Gain in (in $\mathrm{dBi}$ ) & 6.25 & 4.17 & 4.37 & 2.48 \\
\hline Bandwidth (MHz) & $\begin{array}{l}100 \\
600\end{array}$ & $\begin{array}{l}200 \\
900\end{array}$ & $\begin{array}{l}100 \\
600 \\
300 \\
300\end{array}$ & $\begin{array}{l}40 \\
100 \\
100 \\
20 \\
20\end{array}$ \\
\hline VSWR & $\begin{array}{l}1.2 \\
1.003\end{array}$ & $\begin{array}{l}1.31 \\
1.15\end{array}$ & $\begin{array}{l}1.14 \\
1.1 \\
1.02 \\
1.2\end{array}$ & $\begin{array}{l}1.8 \\
1.2 \\
1.06 \\
1.3 \\
1.3\end{array}$ \\
\hline
\end{tabular}

\section{Conclusion}

An octagonal microstrip patch antenna array with gain enhancement is analyzed on four different substrates using the same dimensions. FR4 substrate was found to resonate at two different frequencies $4.6 \mathrm{GHz}$ and $5.5 \mathrm{GHz}$ which falls under the WiMAX and WLAN frequency bands with corresponding bandwidths of $100 \mathrm{MHz}$ and $600 \mathrm{MHz}$ and a better gain of $6.25 \mathrm{~dB}$ as compared to the other substrates (duroid, arlon and rogers) which gave a lower gain. The antenna has a small size which makes it easy to be installed in portable devices. 


\section{References}

[1] Balanis, A. C.(1997). Antenna theory (New York, John wiley \& sons, Inc 1997)

[2] Zhou, R., Niu, H., Ji, F., Wan, L., Mao, X., Guo, H., Xui J., Cao, G., (2016). Band-structure tailoring and surface passivation for highly efficient near-infrared responsive $\mathrm{PbS}$ quantum dot photovoltaics. Journal of Power Sources, 333:107-117.

[3] Yang, N., Caloz, C., Wu, K. (2009). Fixed-beam frequency-tunable phase-reversal coplanar stripline antenna array. Antennas and Propagation, IEEE Transactions on, 57(3):671-681.

[4] Yang, N., Caloz, C., \& Wu, K. (2010). High-efficiency balanced phase-reversal antennas: Principle, bandwidth enhancement, frequency tuning, and beam scanning. In Antenna Technology and Applied Electromagnetics \& the American Electromagnetics Conference (ANTEM-AMEREM), 2010 14th International Symposium.

[5] Bala, B.D; Muhammad, B; Abdu, A.M.; Iliyasu, A.Y; and Tijjani, A.(2017). Microstrip patch antenna array with gain enhancement for wlan applications. Bayero Journal Of Engineering And Technology(Bjet) 12(2):18-25

[6] Kumari, N., Kumar, A..S. Modified Design of Microstrip Patch Antenna for WiMAX Communication System

[7] Yang, N., Caloz, C.,Wu, K. (2008). Substrate integrated waveguide power divider based on multimode interference imaging. In Microwave Symposium Digest, 2008 IEEE MTT-S International, pp. 883886.

[8] RajeshwarLalDua, Himanshu Singh, (2012). 2.45 GHz Microstrip Patch Antenna with Defected Ground Structure for Bluetoothll, IJSCE, ISSN: 2231-2307, Volume-1,

[9] MouloudChallal, A.A., MokraneDehmas. (2011). Rectangular Patch Antenna Performances Improvement Employing Slotted Rectangular shaped for WLAN Applicationsll, IJCSI, Vol. 8, Issue 3, No. 1, May.

[10] Khraisat, Y. S. H. (2012). Design of 4 Elements Rectangular Microstrip Patch Antenna with High Gain for 2.4 GHz Applications. Modern Applied Science, 6(1), pp.68-74. doi:10.5539/mas. 6(1):68

[11] Venkateswaran, A. (2009). Analysis of Planar EBG Structures Using Transmission Line Models, McGill University, Montreal Canada.

[12] Sounas, D. L., Caloz, C. (2011). Graphene-based non-reciprocal metasurface. In Antennas and Propagation (EUCAP), Proceedings of the $5^{\text {th }}$ European Conference on Antennas and Propagation. IEEE, pp. 2419-2422.

[13].Ali, M.T., Jaafar, H., Subahir, S., Yusof, A. L.(2012) "Gain enhancement of air substrate at $5.8 \mathrm{GHz}$ for microstrip antenna array" IEEE conference 978-1-4577-1559-4112

[14] Wang, H., Huang, X.B., Sang, D.G.( 2008). A single layer wideband U-slot microstrip patch antenna array. IEEE antennas and wireless propagation letters, vol. 7,

[15] Horng-Dean, C., Chow-Yen-Desmond, S., Jun-Yi, W., Tsung-Wen, C.(2012). Broadband High-Gain Microstrip Array Antennas for WiMAX Base Station. IEEE transactions on antennas and propagation,vol. 60, no. 8 , august

[16] Iriarte, J. C., Ederra, I., Gonzalo, R., Gosh, A., Laurin, J. J.,Caloz,C.De Maagt, P. (2006). EBG superstrate for gain enhancement of a circularly polarized patch antenna. In Antennas and Propagation Society International Symposium 2006, IEEE,pp. 2993-2996.

[17] Hammerstad, E., Jensen, O.(1980). Accurate Models for Microstrip Computer Aided Design. 1980 IEEE MTT S International Microwave Symposium, Digest, (Washington), pp. 407-409. 